It consists of a thin shell of horn or other translucent substance. The anterior surface presents an aperture in which plain glasses or the glasses commonly used by the cyclist are accurately fitted and allow neither dust nor air to impinge on the eye. The posterior border of the shell can be easily adapted to the parts surrounding the eye with which they are in contact, except in that part which extends towards the ear. Here a groove exists which being separated from the temple, allows a free current of air to the cavity of the chamber between the eye and the glass and thus permits ventilation, whilst it prevents the glass from being dimmed by evaporation.

\title{
IMPROVED ELEOTRODES HOR UTERINE
} APPLICATION.

These consist of an intra-uterine electrode and of an abdominal electrode. The latter Fig. 1 consists of a sheet

FIG. 1.

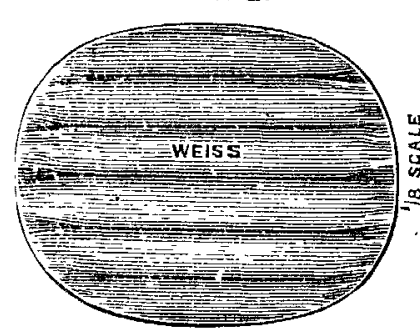

many who advocated active interference. He thought that but little good could come from the College joining with those who were for ever crying out to Hercules for help and invoking the strong arm of the law to protect thei interests and pointed to the example set by Harvey and his compeers who steadfastly pursued their labours in the midst of the turmoil of civil war. Quoting Bacon's words that "every man was a debtor to his profession" he pointed to the College as one of the greatest temples of Esculapias and said that they should never forget they were trustees of a great inheritance. He next pro. ceeded to sketch the lives and characteristics of the sixteen Fellows who had died since the last annual meetingDr. James Andrew, Sir J. C. Bucknill, Dr. J. Braxton Hicks, Dr. F. Chance, Dr. Owen Daly (Hull), Dr. T. Bell Fietcher (Birmingham), Dr. R. Mandy Gover, Dr. A. Hall (Brighton) Dr. C. A. Lockbart Robertson, Dr. W. H. Robertson (Bax ton), Dr. W. Roxbargh (Ipswich), Dr. Jas. Turnball (Liverpool), Dr. Henry Thompson, Dr. William Wadham, Sir R Quain, and Dr. Charles West.

On the motion of $\mathrm{Sir}$ A. GARROD, seconded by the Senion CENson (Dr. Gee), a hearty vote of thanks was accorded to the President for his address.

Sir Samuel Wilks then laid down the insignia of his office and the Fellows proceeded to ballot for the President of the ensuing year. The result was a practically unanimous vote for Sir Samnel Wilks, who received 99 votes from the 103 Fellows present, Dr. Dickinson, Sir R. Douglas Powell, and Sir William Roberts each receiving one vote. Sir Samue Wilks was then inducted into office by the Senior Censor amid applause.

Sir William PRIFSTLEY drew attention to the rumoured changes by the War Office in respect to the rank of army medical officers, from which it would appear that it was pro posed that no medical officer could be promoted beyond the rank of colonel. Sir William Priestley urged that steps should be at once taken to ascertain the truth of this report and if it be substantiated to represent to the Secretary of State for War that such a limitation would be detrimental to the best interests of the service.

Sir JOSEPH FAXRER said that if that proposal were carried into effect it would render futile any other concessions, for if a medical officer were worthy the rank of colonel he was equally entitled to hold that of major-general.

A resolution was carried to take action in the direction indicated by Sir William Priestley.

On the motion of Dr. PoLlock a vote of sympathy was accorded to the family of the late Sir Richard Quain in the great loss they had sustained.

It was reported that at a meeting on March 29th of medical delegates and the London Members of Parliament to urge on the latter the claims of the University of London Commission Bill the College was represented by Dr. Allchin.

The PRESIDENT offered for the acceptance of the College a gift of silver plate presented by the late Sir Richard Quain on Feb. 17th last. The gift comprised a handsome candelabra and other pieces of presentation plate of which the deceased Fellow had been the recipient during his professional career.

On the motion of Sir JOSEPH FAYRER the thanks of the College were directed to be transmitted to the relatives of Sir Richard Quain.

The PRESIDENT also offered for the acceptance of the College a microscope by Ross belonging to the late $\mathrm{Mr}$ Edward Palmer, M.D. St. And., M.R.C.P. Lond, presented by his son.

A communication was read from the secretary of the Royal College of Surgeons of England reporting certain proceeding of the Council on Feb. 10th.

On the invitation of the secretary of the International Congress on Hygiene and Demography to be held at Madrid, April 10th to 17th, Dr. Odling was appointed delegate from the College.

A memorial was read from Dr. Fdmonstone Charles, F.R.C.P., and others connected with the College, asking the College to assist them in protecting the interests of British practitioners in Italy in view of proposed legislation, which would require every foreign practitioner to undergo the curriculum and examinations of that country before being granted permission to practise there.-On the motion of Dr. Bagshawe, seconded by Dr. Cullingworrh, the Presi. dent was authorised to take immediate steps to forward the plea of the memorialists.

Reports were received from the Committee of Management and from the Laboratories Committee. 